\section{Ethylene Exposure Duration Affects Postharvest Needle Abscission in Balsam Fir (Abies balsamea L.)}

\author{
Mason T. MacDonald, Rajasekaran R. Lada ${ }^{1}$, and Alex I. Martynenko \\ Department of Plant and Animal Sciences, Nova Scotia Agricultural College, \\ P.O. Box 550, Bible Hill, NS, B2N 5E3, Canada
}

\section{Martine Dorais \\ Agriculture and Agri-Food Canada, Université Laval, Quebec, QC, G1V 0A6, Canada}

\section{Steeve Pepin and Yves Desjardins \\ Horticultural Research Center, Université Laval, Quebec, QC, G1V 0A6, Canada}

Additional index words. Christmas tree, needle retention, water use, senescence, xylem pressure potential, conifers

\begin{abstract}
Needle loss after harvest is a major problem for Atlantic Canada's Christmas tree and greenery industry. Ethylene is a signal for abscission in balsam fir, but preliminary studies have suggested that the role of ethylene may be influenced by length of exposure. Short-term and long-term ethylene exposure experiments were conducted. Branches were exposed to ethylene for $24 \mathrm{~h}$ (short-term) or continuously (long-term) at concentrations of 0 to $1000 \mathrm{ppm}$. The response variables measured were needle retention duration (NRD), average water use (AWU), and xylem pressure potential (XPP). Shortterm exposure to any concentration of ethylene delayed needle abscission by 30 to 40 days. In contrast, long-term exposure to all concentrations of ethylene accelerated abscission, most evident by a 21-day decrease in NRD at $1000 \mathrm{ppm}$ ethylene. There was a $60 \%$ decrease in NRD, $160 \%$ decrease (more negative) in XPP, and $80 \%$ increase in AWU as a result of long-term exposure to ethylene. Overall, our results demonstrate an opposite effect of short-term and long-term ethylene exposure, which suggests that shortterm exposure to ethylene might help to precondition balsam fir and delay needle abscission during postharvest handling.
\end{abstract}

Balsam fir is a tree typically found in eastern to central Canada and northeastern United States (Burns and Honkala, 1990). Balsam fir is also the principal Christmas tree species grown in Atlantic Canada (a region that includes the provinces of Nova Scotia, New Brunswick, Prince Edward Island, and Newfoundland). Over three million trees are harvested annually from Atlantic Canada, valued at $\$ 72$ million. Of these trees, over $80 \%$ of all balsam fir are shipped to the United States (CTCNS, 2009). Balsam fir trees are preferred by consumers for their unique fragrance, color, and needle density (Burns and Honkala, 1990). To meet demands, balsam fir harvest begins

Received for publication 16 Sept. 2010. Accepted for publication 19 Oct. 2010.

We thank the Nova Scotia Department of Natural Resources for allowing us the use of their Tree Breeding Center in Debert and the generous provision of their genotype identification key. We thank the Natural Science and Engineering Research Council, Atlantic Innovation Fund, and Christmas Tree Council of Nova Scotia for research funding to Dr. Lada. We also thank Dr. Peter Harvard and Dr. Kevin Sibley for internal review of the manuscript.

${ }^{1}$ To whom reprint requests should be addressed; e-mailrlada@nsac.ca. retention of cold-acclimated trees with noncold-acclimated trees. Cold acclimation generally improved needle retention, although the degree of improvement also varied between genotypes (MacDonald and Lada, 2008).

Ethylene is a gaseous plant typically associated with abscission, although it is involved in several physiological processes. Ethylene is a regulator of seed germination, seedling growth, leaf and petal abscission, organ senescence, and stress response (Abeles et al., 1992). In broad terms, ethylene triggers senescence and influences plant growth and morphology (Bleecker and Kende, 2000). Ethylene evolution typically increases after stress conditions such as water deficit, chilling, or mechanical stress (Morgan and Drew, 1997). For example, ethylene evolution increased by $120 \%$ to $300 \%$ in jack pine (Pinus banksiana) and by $110 \%$ in white pine (Pinus strobus) under water deficit (Islam et al., 2003; Rajasekaran and Blake, 1999). As a result of the mechanical stresses associated with harvest and shipping, it has been speculated that balsam fir trees may be exposed to physiologically significant concentrations of ethylene, which accelerate abscission. Accelerated abscission resulting from ethylene occurs in several herbaceous species, including tomato, tobacco, and ornamental flowers (Aharoni et al., 1979; Bleecker and Kende, 2000; Gepstein and Thimann, 1981). It is believed that ethylene induces abscission by increasing production of several hydrolytic enzymes such as cellulase or polygalacturonase, which weaken cell walls of the abscission zone (Sexton and Roberts, 1982; Tucker et al., 1988). Ethylene has also accelerated senescence and abscission by decreasing auxin transport (thereby increasing the sensitivity of a plant to ethylene) and by producing the forces necessary to facilitate abscission (Beyer and Morgan, 1971; Wright and Osborne, 1974).

Only a few studies have been published regarding the role of ethylene in needle abscission of conifers, although it is speculated to work in a similar manner as other plants. In Norway spruce (Picea abies), ethylene increased linearly with needle damage and abscission (Wilksch et al., 1998). In silver fir (Abies alba), increases in ethylene production in response to disease infection were correlated with chlorophyll degradation followed promptly by accelerated abscission of needles (Fuhrer, 1985). Previous work with balsam fir has implicated continuous ethylene exposure as a signal to induce abscission after root detachment (MacDonald et al., 2010). Exogenous ethylene induced abscission after several days of exposure and inhibition of ethylene doubled the time required for abscission Curiously, abscission often occurs in less than $24 \mathrm{~h}$ of ethylene exposure in other species (Brown, 1997) prompting investigations into possible benefits of acute ethylene exposure. A preliminary experiment with balsam fir suggested a 24-h exposure time in balsam fir does not induce abscission but may be beneficial in delaying abscission (MacDonald et al., 2009). It was hypothesized that acute exposure to ethylene may precondition balsam fir to future ethylene responses. Thus, the objective of this 
study was to investigate the effects of both shortand long-term ethylene exposures on needle abscission of 2-year-old balsam fir branches.

\section{Materials and Methods}

Sample collection. Branches were collected from a balsam fir clonal orchard (2-m $\times$ 3-m spacing) at the Tree Breeding Center, Department of Natural Resources, Debert, Nova Scotia, Canada (long. $45^{\circ} 25^{\prime} \mathrm{N}$, lat. $63^{\circ} 28^{\prime} \mathrm{W}$ ). Originally the clonal orchard was a provenance trial where balsam fir trees from various regions of Nova Scotia were evaluated for characteristics such as color, shape, pest resistance, and needle retention and then grafted onto existing rootstock at the Tree Breeding Center. Each sample consisted of a 2-year-old branch $(\approx 30 \mathrm{~cm}$ long and $40 \mathrm{~g})$ cut from the southeastern side of a tree from a height $1.5 \mathrm{~m}$ aboveground. Branches were immediately placed in a container, with cut ends submerged in distilled water, for transport to a growth chamber.

Growth chamber conditions. The protocol for growth chamber conditions and experimental set-up were based on MacDonald et al. $(2009,2010)$. Experiments were conducted in a growth chamber maintained at a $22 / 15{ }^{\circ} \mathrm{C}$ day/night temperature regime, $50 \%$ relative humidity, and $80 \mu \mathrm{mol} \cdot \mathrm{m}^{-2} \cdot \mathrm{s}^{-1}$ light intensity from incandescent and fluorescent lights. Growth chamber conditions were meant to imitate postharvest conditions found in a typical household. Branches were initially weighed and then placed in a $250-\mathrm{mL}$ flask supplied with $200 \mathrm{~mL}$ of distilled water. The neck of each flask was sealed with cotton gauze to reduce direct evaporation and provide added stability to a branch. Afterward, the entire unit was weighed.

All branches were stored in a customdesigned ethylene incubation chamber (EIC) within a growth chamber designed specifically to house a balsam fir branch or seedling, allowing light penetration and providing air circulation (Fig. 1). The main housing of the EIC was an 80-L plastic cylindrical container with a diameter of $48 \mathrm{~cm}$. The lid was a clear Plexiglas designed by B\&D Glass (Truro, Nova Scotia, Canada). Rubber strips circulate the top rim of the container to provide a seal between the lid and container. A small 14-mm hole was drilled $5 \mathrm{~cm}$ from the center of the Plexiglas lid to insert a rubber septum to allow injection and extraction of gases. Temperature and humidity within the EIC were monitored by a hydrometer/thermometer (Orbyx Electronics, Concord, Ontario, Canada) attached to one side of the EIC, whereas the other side had a $10-\mathrm{cm}$ fan attached at a $45^{\circ}$ angle, ensuring circulation without direct airflow onto a branch.

Short-term exposure to ethylene. Two consecutive experiments were conducted to determine the effects of short-term ethylene exposure on abscission. Each experiment followed a completely randomized design, in which a total of 20 branches was exposed to five different concentrations of ethylene $(0,10$, 100,500 , and $1000 \mathrm{ppm}$ ) for $24 \mathrm{~h}$. Branches were collected on 10 Mar. 2008 for the first experiment and 15 May 2008 for the second. Each treatment had four replicates (replicates $=$ one branch). Ethylene concentrations were monitored using a portable ethylene analyzer (Levitt-Safety, Moncton, NB, Canada). The branches were then removed from the EIC and randomly positioned in the growth chamber. In the first experiment, all branches were monitored daily for $70 \mathrm{~d}$, the approximate number of days from commercial harvest until removal of a Christmas display (i.e., $31 \mathrm{Dec}$.). In the second experiment, branches were monitored until complete abscission had occurred (i.e., $80 \mathrm{~d}$ ).

The response variables in the first experiment were percentage needle loss and AWU after $80 \mathrm{~d}$. Response variables in the second experiment were NRD, AWU, XPP, and chlorophyll index. In the second experiment, NRD replaced percentage needle loss as the primary indicator of abscission. Detailed descriptions of response variables can be found subsequently.

Long-term exposure to ethylene. Two experiments were conducted to determine the effects of long-term ethylene exposure on abscission. Branches were collected on 10 Mar. 2008 for the first experiment and 15 May 2008 for the second. In the first experiment, 20 branches were continuously exposed to 0,10 , 100,500 , or $1000 \mathrm{ppm}$ with four replications per treatment as described in MacDonald et al. (2010). Branches were removed after $24 \mathrm{~h}$ to determine needle loss and water use, replaced, and then ethylene was reintroduced to the
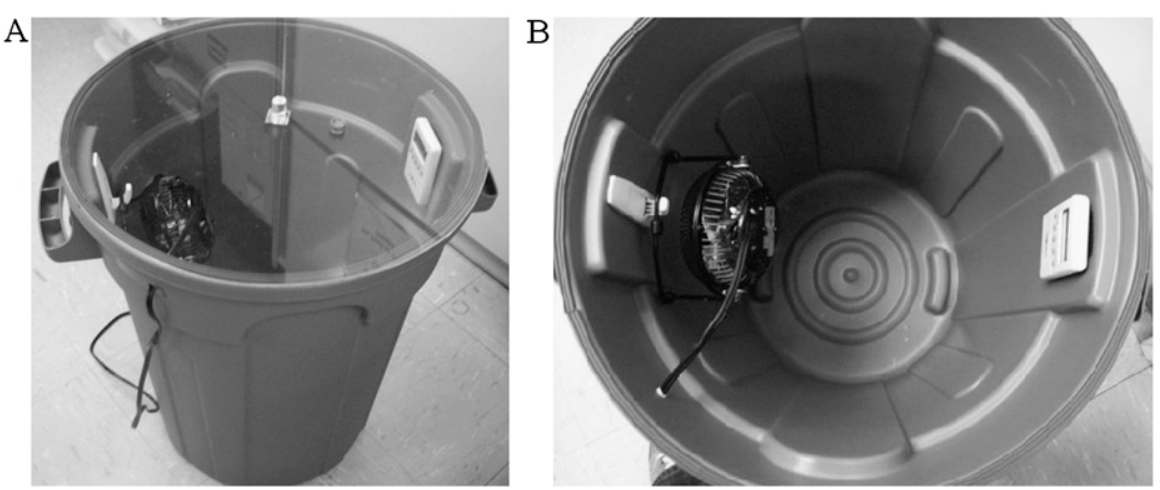

Fig. 1. Ethylene incubation chamber. (A) Exterior view; (B) interior view. chamber. This process continued for $14 \mathrm{~d}$. Branches were then observed until complete abscission had occurred in all branches (i.e., $34 \mathrm{~d}$ ). The response measurements were percent needle loss, NRD, and AWU. The second experiment was similar to the first, but with only $0-p p m$ and $1000-p p m$ ethylene treatments, each replicated 10 times. The number of replications was increased as a result of having only two treatments. The response measurements were AWU, NRD, XPP, and chlorophyll index.

Needle loss and needle retention duration. Percentage needle loss was determined by calculating the ratio of needle mass lost each day to total branch fresh weight. Needle retention duration was defined as the length of time required to lose half of a branch's initial fresh weight through abscission as described in previous studies (MacDonald and Lada, 2008; MacDonald et al., 2009, 2010).

Average water use. Average daily water use $\left(\mathrm{mL} \cdot \mathrm{g}^{-1} \cdot \mathrm{d}^{-1}\right)$ was determined gravimetrically using the following equation:

$$
\begin{aligned}
& \mathrm{AWU}= \\
& \frac{\text { Initial mass }- \text { Final mass }+ \text { Needle mass }}{\text { Time }}
\end{aligned}
$$

Xylem pressure potential. The XPP of branches was measured after $14 \mathrm{~d}$ using a Plant Moisture System Pressure Bomb (PMS Instrument Co., Cornwallis, OR). A clipping from the main branch was mounted upside down inside a pressure chamber and pressure was increased until the water droplets appeared. The minimum pressure required to release a water droplet was recorded.

Chlorophyll index. A Minolta SPAD 504 $\mathrm{m}$ (Konica Minolta, Ramsey, NJ) was used to record the relative chlorophyll index of the needles from each branch after $14 \mathrm{~d}$. Several needles were used to cover the sensor and the instrument measured the transmittance by needles at two wavelengths (650 $\mathrm{nm}$ and $940 \mathrm{~nm}$ ) that are differentially absorbed by chlorophyll. Results were averaged from five readings from each replicate.

Statistical analysis. Linear regression analysis using Minitab 15 (Minitab 15; Minitab Inc., State College, PA) was used to analyze percentage needle loss using time (days) as the explanatory variable. NRD, XPP, AWU, and chlorophyll index in the short-term ethyleneexposure experiment and NRD in the longterm ethylene exposure experiment were submitted to both linear and non-linear regression. A two-sample $t$ test was used to detect significant differences in NRD, XPP, AWU, and chlorophyll index in the final experiment.

\section{Results}

Short-term exposure to ethylene. It was apparent after visual inspection that a $24-\mathrm{h}$ exposure to ethylene delayed abscission in balsam fir branches (Fig. 2). In the first experiment, branches exposed to $500 \mathrm{ppm}$ or $1000 \mathrm{ppm}$ ethylene for $24 \mathrm{~h}$ had significantly $(P<0.001)$ less needle loss $(39.3 \%$ and $13.6 \%$, respectively) compared with the 
control $(70.3 \%)$ after 70 d. Regression analysisconfirmed a significant $(P<0.001)$ linear relationship between concentration and percentage needle loss (Fig. 3A). In the second experiment, 24-h ethylene exposure significantly $(P=0.032)$ increased NRD compared with the control (Table 1; Fig. 3B). A 10-, 100-,

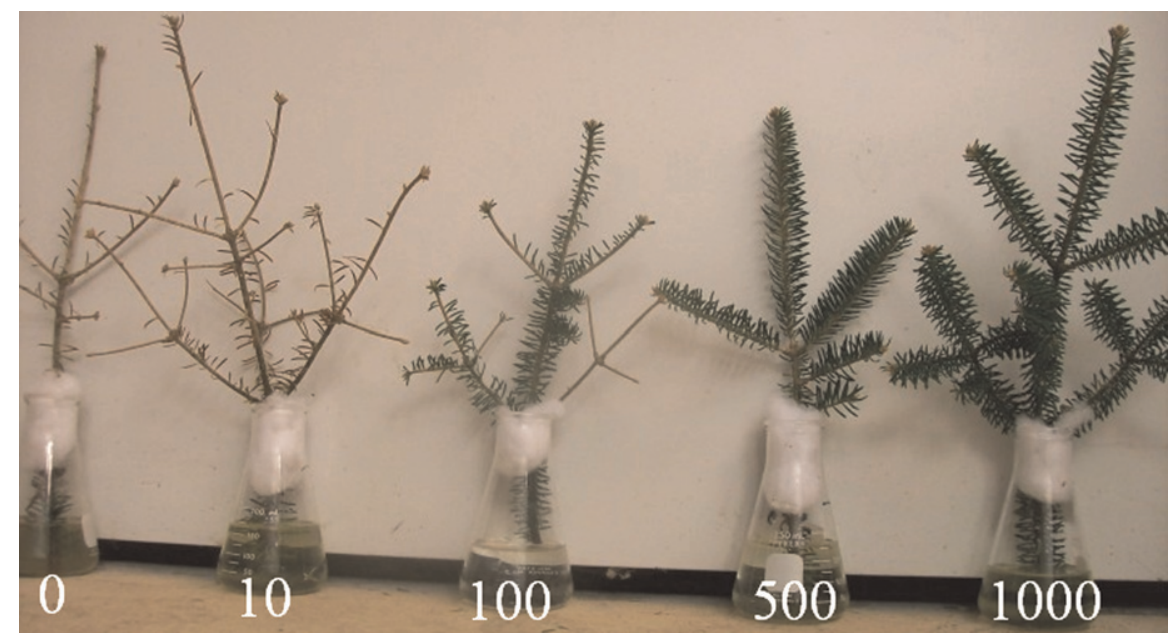

Fig. 2. Example of needle loss at Day 70 of balsam fir branches exposed to different concentration (ppm) of ethylene for $24 \mathrm{~h}$.

A
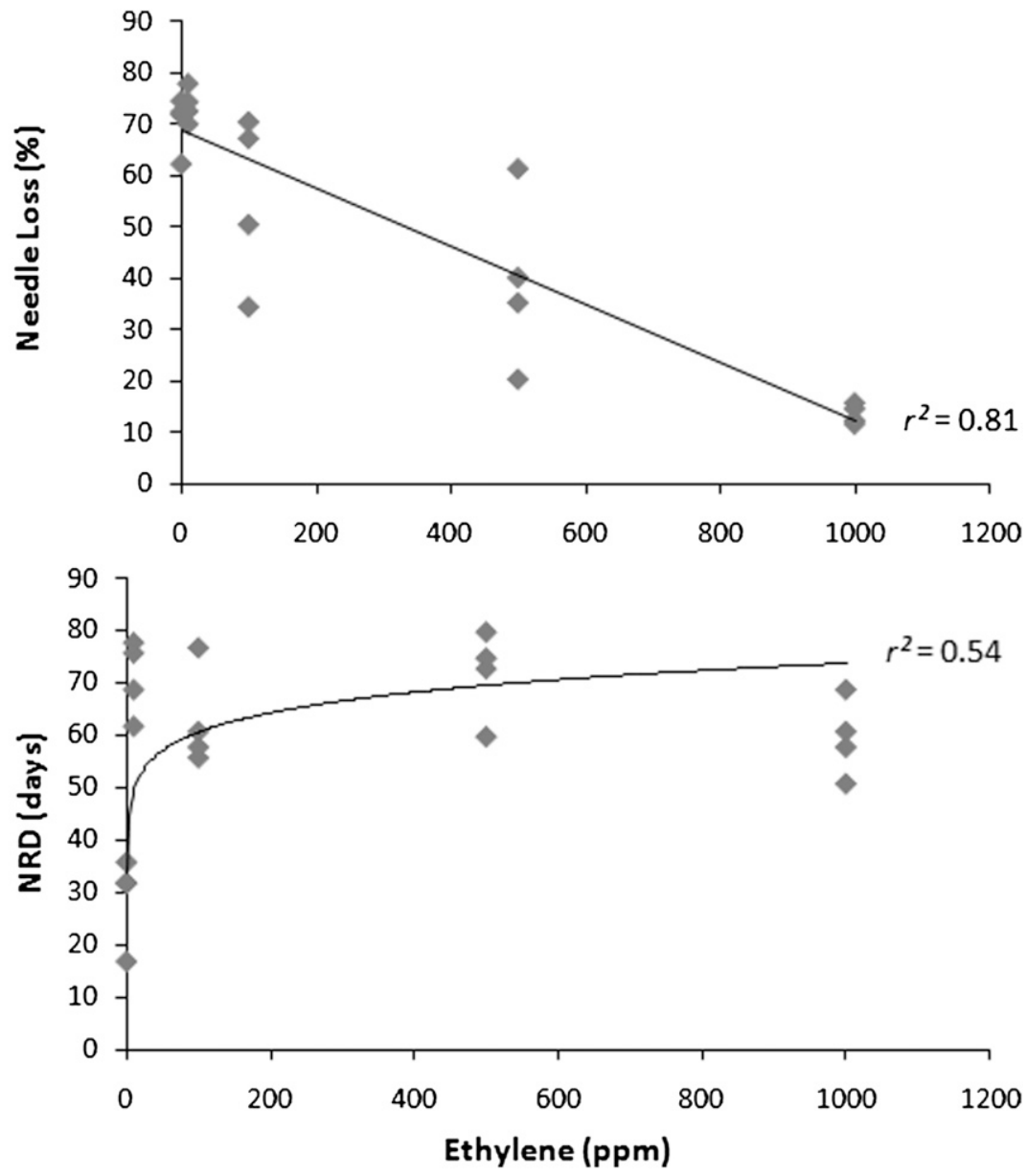

Fig. 3. Significant $(P<0.001)$ relationships between short term $(24-\mathrm{h})$ ethylene exposure concentration and (A) percentage needle loss in balsam fir at Day 70 described by needle loss $=0.06$ ethylene +68.68 and (B) needle retention duration described by NRD $=41.1$ ethylene ${ }^{0.09}$ from two separate experiments. $\mathrm{NRD}=$ needle retention duration .
Long-term exposure to ethylene. Continuous ethylene exposure for $14 \mathrm{~d}$ significantly $(P<0.001)$ decreased NRD at all concentrations (Fig. 4). However 1000 ppm ethylene had the most severe effect on NRD, which decreased from an average of $30 \mathrm{~d}$ to $13 \mathrm{~d}$ ( $\approx 57 \%$ decrease). Continuous exposure to $1000 \mathrm{ppm}$ caused needle abscission to begin Day 5, and needle loss increased exponentially afterward (Figs. 5 and 6).

The second long-term exposure experiment compared the effects of only 1000 ppm ethylene (on NRD, AWU, XPP, and chlorophyll index) with a control. Exposure to 1000 ppm ethylene significantly decreased NRD from $35 \mathrm{~d}$ to $14 \mathrm{~d}(\approx 60 \%$ decrease $)(P<0.001)$ and $\mathrm{XPP}$ from $-0.16 \pm 0.02 \mathrm{MPa}$ to $-0.42 \pm 0.07$ $\mathrm{MPa}(P=0.005)$, whereas AWU increased from $0.05 \pm 0.007 \mathrm{~mL} \cdot \mathrm{g}^{-1} \cdot \mathrm{d}^{-1}$ to $0.09 \pm 0.008$ $\mathrm{mL} \cdot \mathrm{g}^{-1} \cdot \mathrm{d}^{-1}(P<0.001)$. There was no significant influence on chlorophyll index (19.94 $\pm 2.50)$ (Table 1).

\section{Discussion}

These results show that exposure to ethylene can influence needle abscission in balsam fir. A 24-h exposure period (0 to $1000 \mathrm{ppm}$ ) increased NRD by $90 \%$ to $140 \%$, whereas continuous ethylene exposure decreased NRD by $30 \%$ to $70 \%$. These results were not completely unexpected based on studies with other species, which found that exogenous ethylene induces abscission (Aharoni et al., 1979; Bleecker and Kende, 2000; Gepstein and Thimann, 1981). In addition, MacDonald et al. (2010) recently reported that continuous exposure to ethylene at high concentrations induced abscission in balsam fir and blocking this signal delayed abscission. However, there are no published reports of ethylene delaying abscission, at short-term exposure or lower concentrations, as noted here for balsam fir.

Ethylene is ineffective at inducing abscission in as many as $60 \%$ of herbaceous species (Abeles et al., 1992). However, those studies are often conducted on plants with roots still connected to their roots, where it may be difficult to detect a delay in leaf abscission. When attached to roots, abscission primarily occurs as a response to disease or shading (Patterson and Bleecker, 2004). Thus, ethylene would either induce abscission or there would be no observed effect. During harvest, a plant is separated from its roots, which triggers a cascade of events resulting in abscission that would not have occurred otherwise. In this case, it would be possible to report accelerated abscission, no change, or delayed abscission.

In some aspects, the relationship between ethylene concentration and abscission response was very similar. In both short-term and longterm ethylene exposure, a concentration of 10 ppm ethylene was sufficient to induce a significant abscission response (be it an acceleration or a delay) and there was very little additional response above $100 \mathrm{ppm}$. Thus, we can assume that relatively low concentrations of ethylene are sufficient to saturate ethylene receptors, as noted by Sisler et al. (1999). Ethylene receptor saturation between 10 and 100 ppm also seems 
Table 1. Summary of abscission parameters for balsam fir branches exposed ethylene continuously (long-term) or for $24 \mathrm{~h}$ (short-term). ${ }^{\mathrm{z}}$

\begin{tabular}{|c|c|c|c|c|c|c|c|c|c|c|}
\hline \multirow[b]{2}{*}{ Concn (ppm) } & \multicolumn{5}{|c|}{ Short-Term Exposure } & \multicolumn{5}{|c|}{ Long-Term Exposure } \\
\hline & 0 & 10 & 100 & 500 & 1000 & 0 & 10 & 100 & 500 & 1000 \\
\hline NRD (days) & $29.3^{\mathrm{a}}$ & $71.3^{\mathrm{b}}$ & $63.0^{\mathrm{b}}$ & $72.0^{\mathrm{b}}$ & $59.8^{\mathrm{b}}$ & $29.8^{\mathrm{a}}$ & $20.3^{\mathrm{b}}$ & $16.8^{\mathrm{c}}$ & $16.3^{\mathrm{c}}$ & $13.3^{\mathrm{d}}$ \\
\hline $\operatorname{AWU}\left(\mathrm{mL} \cdot \mathrm{g}^{-1} \cdot \mathrm{d}^{-1}\right)$ & 0.06 & 0.06 & 0.05 & 0.04 & 0.05 & $0.05^{\mathrm{a}}$ & - & - & - & $0.09^{\mathrm{b}}$ \\
\hline XPP (-MPa) & 0.40 & 0.35 & 0.20 & 0.38 & 0.30 & $0.16^{\mathrm{a}}$ & - & - & - & $0.42^{\mathrm{b}}$ \\
\hline Chlorophyll index & 8.5 & 10.5 & 15.2 & 12.1 & 14.4 & 18.8 & - & - & - & 21.0 \\
\hline
\end{tabular}

${ }^{\mathrm{z} D i f f e r e n t ~ l e t t e r s ~ i n d i c a t e ~ a ~ s i g n i f i c a n t ~ d i f f e r e n c e ~ a t ~} \alpha=0.05$.

$\mathrm{NRD}=$ needle retention duration; AWU = average water use; XPP = xylem pressure potential.

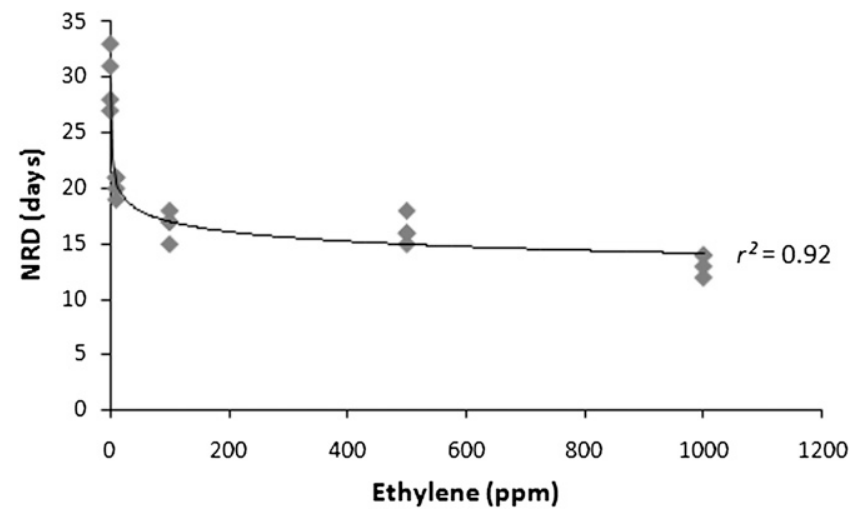

Fig. 4. Significant $(P<0.001)$ relationship between continuous ethylene exposure for $14 \mathrm{~d}$ and needle retention duration. The relationship is described by $\mathrm{NRD}=24.6$ ethylene $^{-0.08} . \mathrm{NRD}=$ needle retention duration.

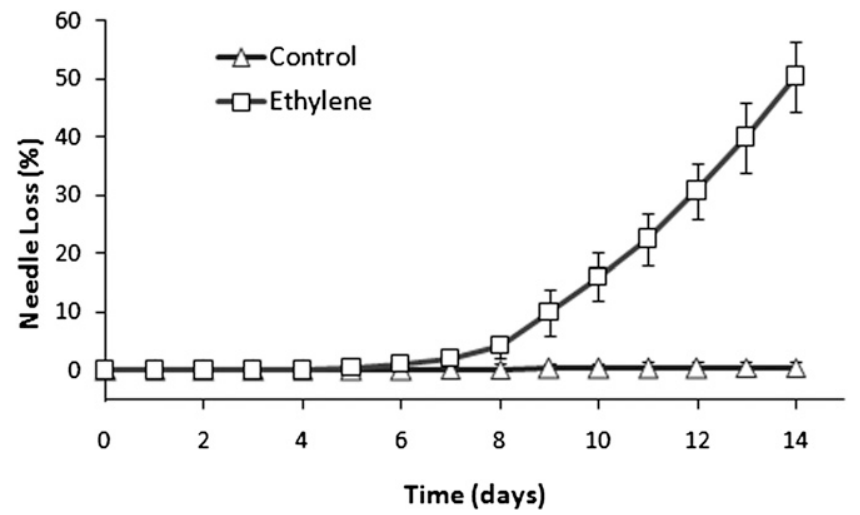

Fig. 5. Progression of needle loss of long-term exposure to $0 \mathrm{ppm}$ (control) ethylene and $1000 \mathrm{ppm}$ ethylene in balsam fir branches. Percentage needle loss was determined by mass of needles lost compared with total mass of branch from four replicates. Vertical bars are expressing SE.
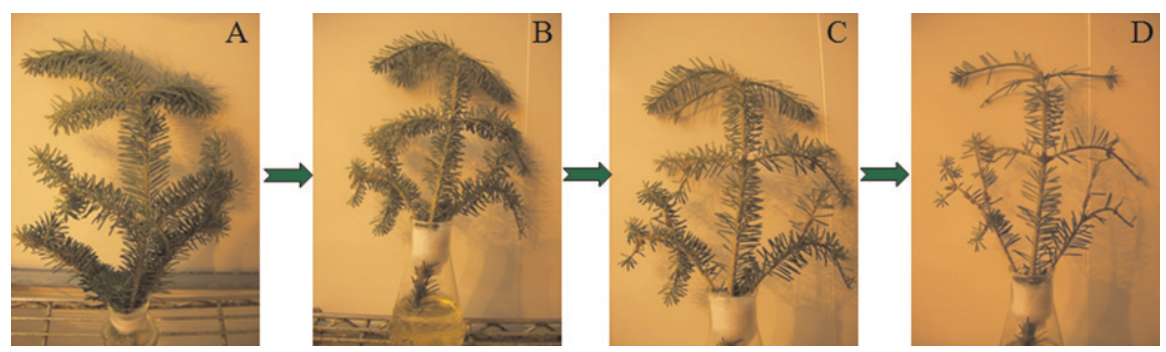

Fig. 6. Progression of needle loss in a balsam fir branch after continuous exposure to 1000 ppm ethylene after: (A) 0 d; (B) $8 \mathrm{~d}$ (2.2\% needle loss); (C) $11 \mathrm{~d}$ (16.8\% needle loss); (D) $13 \mathrm{~d}$ (33.3\% needle loss). reasonable from a biological perspective; a previous study with balsam fir identified endogenous ethylene concentration between 11.8 and 20.5 ppm (MacDonald et al., 2010).

The opposite effect of the short-term and long-term effect of ethylene on balsam fir needle abscission observed in our experiments supports the synthesis-degradation balance theory suggested by Brown (1997), in which ethylene may influence both cell wall synthesis and degradation at the abscission zone. The synthesis-degradation balance shifts to cell wall synthesis if ethylene concentration or sensitivity is low, whereas the balance shifts to cell wall degradation if concentration or sensitivity is high. A previous study showed that ethylene-induced transcripts disappeared in bean leaf abscission zones when the partial pressure of ethylene was reduced using hypobaric chambers (Sexton et al., 1985). The abscission process not only halts if ethylene declines before a certain point, but is reversed and the force required to abscise is increased (Abeles et al., 1992; Brown, 1997).

In many plant species, one of the first apparent ethylene-induced changes is a loss of chlorophyll (Jacob-Wilk et al., 1999). Ideally, before abscission occurs, there is a massive relocation of carbon, nitrogen, and other minerals to other parts of a plant, which explains the visual loss of pigmentation (BuchananWollaston, 1997). There was no ethyleneinduced chlorophyll degradation in balsam fir. Ethylene-induced abscission has occurred independent of senescence in some species (Abeles et al., 1992; Morgan and Drew, 1997), but the significance of senescence-independent abscission in balsam fir is unknown.

There is a consistent relationship between water use and needle abscission in balsam fir. Branches with low needle retention (as a result of long-term ethylene exposure) used $80 \%$ more water than control branches. Previous studies also observed this inverse relationship between water use and needle loss in the presence of ethylene inhibitors and after cold acclimation (MacDonald et al., 2010; Lada and Thiagarajan, 2006, unpublished report), i.e., needle retention was high in instances in which average daily water use was low. A higher water use would likely indicate higher transpiration and, subsequently, a less negative XPP. The involvement of ethylene in water relations or regulation is conflicted with results differing between species and environmental conditions. Several studies report that ethylene prevents stomatal closure (Merritt et al., 2001; Tanaka et al., 2005) and consequently increases transpiration (Azuma et al., 2003). In our experiments, it is possible 
that ethylene-inhibited stomatal closure could explain why branches with low needle retention used more water. However, XPP decreased at the same time AWU increased, which cannot be explained. It is recommended that future studies investigate the dynamics of transpiration, stomatal conductance, and water potential to fully understand this relationship.

Both short-term and long-term ethylene exposure results may have practical significance for the Christmas tree industry. First, if producers expose their trees to 10 to 1000 ppm ethylene for $24 \mathrm{~h}$ after harvest, abscission may be significantly delayed. Needle shed is thought to be the primary reason that artificial trees are gaining favor in the market over natural trees, so any delay in abscission is important to producers. Short-term ethylene exposure needs to be investigated at a whole tree level and methodology such as timing, duration, and concentration of ethylene exposure needs to be refined. Second, the cause of ethylene synthesis in trees after harvest must be investigated. MacDonald et al. (2010) reported ethylene synthesis rates after harvest at $20 \mu \mathrm{L} \cdot \mathrm{g}^{-1} \cdot \mathrm{h}^{-1}$, which induced abscission. Our results confirm that prolonged exposure to ethylene will induce abscission but cannot confirm the trigger required for ethylene synthesis to begin. It was previously speculated that mechanical wounding would trigger ethylene synthesis as observed in other species (Morgan and Drew, 1997). However, the length of time among wounding, ethylene synthesis, and eventual abscission is too long. If the signal for ethylene synthesis can be identified, it is likely that other mitigating technologies could be developed.

A potential concern from this study was the experiments were conducted on branches collected in spring instead of fall; thus, they would not be experiencing any cold acclimation. Christmas tree harvest in Nova Scotia typically begins in October and continues until December; thus, commercial trees will often undergo some degree of cold acclimation, which greatly increases needle retention in balsam fir (MacDonald and Lada, 2008). However, comparison of our experiments to previous studies suggests that cold acclimation does not influence the effect of ethylene. Previous work on short-term ethylene exposure on branches collected in fall and winter had very similar results, where NRD was two times higher than a 0-ppm control (MacDonald et al., 2009). Similarly, previous work on long-term ethylene exposure found that NRD decreases by between $50 \%$ and $70 \%$ compared with a control (MacDonald et al., 2010).

\section{Conclusion}

Continuous exposure to concentrations as low as $10 \mathrm{ppm}$ ethylene will significantly accelerate abscission of balsam fir needles after harvest. However, an acute exposure of ethylene (i.e., $24 \mathrm{~h}$ ) at concentrations ranging from 10 to $1000 \mathrm{ppm}$ will significantly delay exposure. The mode of action is not yet completely understood, but there is a potential for practical application to the Christmas tree industry.

\section{Literature Cited}

Abeles, F.B., P.W. Morgan, and M.E. Saltveit 1992. Ethylene in plant biology. 2nd Ed. Academic Press, San Diego, CA.

Aharoni, N., M. Lieberman, and H.D. Sisler. 1979. Patterns of ethylene production in senescing leaves. Plant Physiol. 64:796-800.

Azuma, T., T. Hatanaka, N. Uchida, and T. Yasuda. 2003. Enhancement of transpiration by ethylene is responsible for absence of internodal elongation in floating rice at low humidity. J. Plant Physiol. 160:1125-1128.

Beyer, M.E. and W.P. Morgan. 1971. Abscission: The role of ethylene modification of auxin transport. Plant Physiol. 48:208-212.

Bleecker, A.B. and H. Kende. 2000. Ethylene: A gaseous signal molecule in plants. Annu. Rev. Cell Dev. Biol. 16:1-18.

Brown, K.M. 1997. Ethylene and abscission. Physiol. Plant. 100:567-576.

Buchanan-Wollaston, V. 1997. The molecular biology of leaf senescence. J. Expt. Bot. 48:181199.

Burns, R.M. and B.H. Honkala. 1990. Silvics of North America: 1. Conifers; 2. Hardwoods. Agriculture Handbook 654. U.S. Department of Agriculture, Forest Service, Washington, DC. 2:877.

Chastagner, G.A. and K.L. Riley. 2003. Postharvest quality of noble and Nordmann fir Christmas trees. HortScience 38:419-421.

CTCNS. 2009. The Christmas Tree Council of Nova Scotia. 23 June 2009. <http://www.ctens. $\operatorname{com} />$.

Davis, A.K. 1996. The history of the Christmas tree industry in North America. American Christmas Tree J. 40:5-11.

Fuhrer, J. 1985. Ethylene production and premature senescence of needles from fir trees (Abies $a l b a)$. For. Pathol. 15:227-236.

Gepstein, S. and K.V. Thimann. 1981. The role of ethylene in the senescence of oat leaves. Plant Physiol. 68:349-354.

Islam, M.A., T.J. Blake, F. Kocacina, and L. Rajasekaran. 2003. Ambiol, spermine, and aminoethoxyvinylglycine prevent water stress and protect membranes of Pinus strobus L. under drought. Trees (Berl.) 17:278-284.

Jacob-Wilk, D., D. Holland, E.E. Goldschmidt, J. Riov, and Y. Eyal. 1999. Chlorophyll breakdown by chlorophyllase: Isolation and functional expression of the Chlasel gene from ethylene treated Citrus fruit and its regulation during development. Plant J. 20: 653-661.

MacDonald, M.T. and R.R. Lada. 2008. Cold acclimation can benefit only the clones with poor needle retention duration (NRD) in balsam fir. HortScience 43:1273 (abstr.).

MacDonald, M.T., R.R. Lada, A.I. Martynenko, M. Dorais, S. Pepin, and Y. Desjardins. 2009. Ethylene modulates needle abscission in rootdetached balsam fir. HortScience 44:1142 (abstr.).

MacDonald, M.T., R.R. Lada, A.I. Martynenko, M. Dorais, S. Pepin, and Y. Desjardins. 2010. Ethylene triggers needle abscission in rootdetached balsam fir. Trees 24:879-886.

Merritt, F., A. Kemper, and G. Tallman. 2001. Inhibitors of ethylene synthesis inhibit auxininduced stomatal opening in epidermis detached from leaves of Vicia faba L. Plant Cell Physiol. 42:223-230.

Mitcham-Butler, E.J., L.E. Hinesley, and D.M. Pharr. 1988. Effect of harvest date, storage temperature, and moisture status on postharvest needle retention of Fraser fir. J. Environ. Hort. 6:1-4.

Morgan, P.W. and M.C. Drew. 1997. Ethylene and plant responses to stress. Physiol. Plant. 100: 620-630.

Patterson, S.E. and A.B. Bleecker. 2004. Ethylenedependent and -independent processes associated with floral organ abscission in Arabidopsis. Plant Physiol. 134:194-203.

Rajasekaran, L.R. and T.J. Blake. 1999. New plant growth regulators protect photosynthesis and enhance growth under Jack pine seedlings. J. Plant Growth Regul. 18:175-181.

Sexton, R., L.N. Lewis, A.J. Trewavas, and P. Kelly. 1985. Ethylene and abscission, p. 173196. In: Roberts, J.A. and G.A. Tucker (eds.). Ethylene and plant development. Butterworths, London, UK.

Sexton, R. and J.A. Roberts. 1982. Cell biology of abscission. Annu. Rev. Plant Physiol. 33: 133-162.

Sisler, E.C., M. Serek, E. Dupille, and R. Goren. 1999. Inhibition of ethylene responses by 1 methylcyclopropene and 3-methylcyclopropene. Plant Growth Regulat. 27:105-111.

Tanaka, Y., T. Sano, M. Tamaoki, N. Nakajima, N. Kondo, and S. Hasezawa. 2005. Ethylene inhibits abscisic acid-induced stomatal closure in Arabidopsis. Plant Physiol. 138:23372343.

Tucker, M.L., R. Sexton, E. del Campillo, and L.N. Lewis. 1988. Bean abscission cellulase. Plant Physiol. 88:1257-1262.

Wilksch, W., V. Schmitt, and A. Wild. 1998 Ethylene-biosynthesis in conifers: Investigations on the emission of ethylene and the content of ACC and MACC in Norway spruce (Picea abies) and silver fir (Abies alba). Chemosphere 36:883-888.

Wright, M. and D. Osborne. 1974. Abscission in Phaseolus vulgaris. The positional differentiation and ethylene induced expansion growth of specialized cells. Planta 120:163-170. 